\title{
Sexualidade do Homem na Terceira Idade 4
}

Ri a do da Cunha Caval anti ${ }^{1}$

\section{NTRODUÇ O}

ta fo ma, ada indivíduo onst ói sua $v$ lhi quando la $\mathrm{h}$ ga $\mathrm{l}$ viv aquilo qu onst uiu Com isto $\mathrm{s}$ qu -diz qu a $s$ xualidad do hom $m$ idoso é, $m g$ and pa $t$, um fl xo $d$ sua vida $s$ xual passada

É la o qu $\mathrm{t}$ mos d $\mathrm{l}$ va $\mathrm{m}$ onta a xistên ia d tos fato $s$ biológi os p óp ios da idad, mas é p iso nt nd qu a anatomia a fisiologia s xológi a da $\mathrm{t}$ i a idad stá ins ida d $\mathrm{n}$ t o do ont xto d modifi açõ s qu sof o ganismo omo um todo

Qu m quis nt nd o hom m, qualqu qu $s$ ja sua idad ou $\mathrm{s}$ xo, ultu a, $\mathrm{t}$ mpo ou país $\mathrm{m}$ qu viv, $\mathrm{t}$ á $\mathrm{d}$ studá-lo sob os asp tos biopsi o-só io- ultu ais $\mathrm{T}$ á $\mathrm{d}$ omp nd o hom $\mathrm{m}$ d sd sua ondição mais plu al, a ondição biológi a, omum a todos os out os hom ns Plu alidad qu vai s to nando ada $\mathrm{v} \mathrm{z}$ mais singula, à $\mathrm{m}$ dida qu $\mathrm{s}$ obs va qu o hom $\mathrm{m} \mathrm{t} \mathrm{m}$ oisas qu são omuns a out os hom ns do s u g upo só io- ultu al A singulaidad ating o s u ponto máximo om os asp tos psi ológi os, fa$\mathrm{z}$ ndo om qu o ol tivo biológi o a plu alidad ultu al $\mathrm{s}$ to $\mathrm{n} \mathrm{m}$ úni os individualizados $\mathrm{m}$ ada $\mathrm{p}$ ssoa Subm tido às $\mathrm{m}$ smas $\mathrm{g}$ as $\mathrm{g}$ ais da natu $\mathrm{za}$, viv ndo $\mathrm{mum} \mathrm{m}$ io ultu al omum om out os hom ns d uma m sma so i dad, ada indivíduo é únio na sua ondição psi ológi a Cada um é dif nt do out o 
Teremos, portanto, de estudar a sexualidade na terceira idade sob o ponto de vista geral, biológico; em seguida estudá-la em uma dimensão menos globalizante que é como a cultura encara a velhice e, finalmente, atingir a um indivíduo específico, peculiar, aquela pessoa idosa em si.

\section{O COMPONENTE BIOLÓGICO}

Do ponto de vista biológico, e aqui não vou considerar as possíveis eventualidades de doenças que modificam o quadro, é natural que nos processos de transformações orgânicas, pelas quais passa o indivíduo, o sexo também se modifique. Modificar é uma coisa, morrer é outra e logo se pode dizer que atividade sexual não é privilégio de jovem, mas é uma prerrogativa da vida. Ela se inicia com a vida e morre com a morte. Esta figura do indivfduo dessexualizado pela idade é puramente mítica.

O desejo sexual e a necessidade sexual continuam preservadas ao longo de toda a terceira idade, porque a idade não emudece sexualmente ninguém. Como qualquer criatura, o homem idoso tem necessidades e desejos sexuais. A sua sexualidade não é melhor nem pior que a do jovem; é diferente. Há alguns fatos biológicos que ocorrem com a sexualidade do homem na terceira idade que caracterizam bem esta diferença.

Como ser vivo pertencente a uma espécie zoológica, o homem obedece, como todos os outros seres vivos, a certas leis da natureza. A mais importante destas leis é a conservação da espécie. O homem pode morrer como indivíduo, mas a espécie tem de permanecer viva. E esta permanência se faz através da reprodução e, biologicamente, o sexo é visto como um caminho para a reprodução da espécie; uma necessidade filogênica de continuar a chama da vida.

E se bem que o homem idoso nunca perca totalmente a capacidade reprodutiva, esta missão biológica de preservação da espécie é conferida ao homem e à mulher adultos. Fica fora, portanto, desta obrigação, os idosos e as crianças. Mas, tanto os idosos quanto as crianças têm sexualidade, só que ela é bem mais difusa que a sexualidade do adulto. Na vida adulta, ela é predominantemente genitálica, porque é unindo os genitais que as pessoas irão reproduzir. Todo indivíduo tem zonas erógenas mas, nos adultos, as principais zonas de erotismo são as genitálicas. A expressão da atividade sexual mais importante é a relação pênis/vagina, que em termos biológicos se exprime pela relação espermatozóide/óvulos.

No idoso e na criança, como a imposição reprodutiva da 
natureza não é grande, a sexualidade é difusa. As zonas erógenas são agradáveis por igual. Há sexualidade em todos os toques corporais, há um compromisso menor com o pênis e com a vagina, porque aqui não há o impulso imperioso da reprodução. O sexo da criança a do idoso é essencialmente prazer, é sensorial. Isto não é pior nem melhor que a sexualidade do adulto. E simplesmente diferente.

Volto a insistir que é muito comum se dizer que o desejo sexual diminui com a idade. Isto não é verdade. Eu concordo contudo com a afirmativa de que, com a idade, diminui a freqüência de pensamentos sexuais. É sabido que, em nossa cultura, o homem é mais sexual e a mulher é mais sensual. Deixando de lado as exceções, as mulheres tendem a avaliar os homens pelo aspecto romântico, mas o homem quando avalia uma mulher o faz em termos nitidamente sexuais, em termos de peito, bumbum, coxa e devaneios eróticos. Estudos demonstram que os homens pensam em sexo e sonham com sexo três vezes mais do que as mulheres.

Existem pesquisas que comprovam que até os 40 anos o homem, em termos médios, pensa em sexo quase seis vezes no espaço de uma hora. "Isto quer dizer que os pensamentos sexuais estão o dia inteiro circulando na cabeça dos homens". Ora são as formas da secretária, o bumbum da colega de trabalho, as pernas da moça loura que subiu no elevador, a menina da capa da revista, a tesuda da gatinha que estacionou o automóvel, os peitos da dona da lanchonete, etc.

Quando o indivíduo chega. aos 40 anos, a freqüência dos pensamentos sexuais diminui um pouco. "Ele agora só pensa em sexo uma vez a cada meia hora e lá pelos 50 anos são poucos os homens que pensam em sexo mais do que uma vez por hora".

Qualquer homem pode fazer um teste rápido. "Se sua média for a metade de um homem normal, mesmo assim você anda com o sexo na cabeça muito mais do que qualquer mulher normal".

O homem idoso, portanto, tem seus pensamentos e devaneios sexuais. As coisas se tornam mais diferentes quando se trata do comportamento sexual expresso, isto é, da resposta sexual. O paradoxo é evidente: a cabeça está boa, mas o pênis não responde com a força da fantasia. Há um lamentável descompasso.

"Muitas pessoas idosas podem pensar que são capazes de dar duas, mas esta idéia lhe ocorre sempre antes da primeira. Depois dela, ele se convence que esta capacidade era mental e não física".

Parece incrível que se tenha de reafirmar o óbvio: de que a criança é criança, o adulto é adulto e o idoso é idoso. É evidente que o idoso não pode viver a vida do adulto, nem o adulto a vida da criança. Muitos dos mitos, das crendices, dos desesperos, das 
ansiedades e das depressões do idoso decorrem do fato de que eles, desconhecendo as modificações que a idade determina em sua sexualidade, interpretam estas reações como perda progressiva da virilidade.

Masters e Johnson descobriram e divulgaram as modificações miotônicas e vasocongestivas que ocorrem na resposta sexual dos idosos. Há algumas que são tão pouco ostensivas que quase ninguém repara. Por exemplo, com a idade, diminui o poder contrátil do esfíncter anal na fase orgásmica e já não se nota o chamado "espasmo cargo-pedal" após os 60 anos. Também o sexual flush e a turgidez do mamilo é coisa do passado. Mas que importância pode ter estas modificações para o homem idoso de nossa cultura? Seguramente muito pouco. Pequeno significado para ele terá também se acidentalmente constatar que o testículo do velho aumenta muito pouco com a vasocongestão e que ele não se eleva na fase final de excitamento como no jovem.

Para o homem da cultura ocidental, latino, sul-americano, brasileiro, pouco importa que o testículo fique inerte no fundo do saco escrotal. Em termos de sexo o que ele deseja é que o pênis levante. E isto é um fenômeno muito mesclado com as influências culturais. Ser homem é ter pênis que levanta e quanto maior o pênis, melhor. Se o pênis é pequeno o indivíduo se considera meio homem e se ele não se eleva ele simplesmente se evaporou como homem. O impotente fica na mesma situação da história: tem cara de homem, tem voz de homem, tem jeito de homem, mas... não é homem.

Nós vivemos em uma cultura em que a penilatria é um fato. $\mathrm{O}$ que importa não é o homem que leva o pênis, mas o pênis que leva o homem. O pênis é tão importante, tão deificado, que eu não reluto em divulgar, entre as mulheres, que se no ato sexual não forem tagarelas pelo menos não se mantenham caladas. Elogiem seu homem. Elogiem o pênis do seu homem, mesmo que ele seja uma droga, elogie. Afinal não é possível que ele não tenha nada que seja elogiável. Isto é muito importante para conquistar e manter o seu homem. Dizer que o pênis dele é bonito, elegante, magnífico, é essencial. É como diz Reuben: "quanto mais você se comportar como se o pênis dele fosse uma espécie de poste totêmico a ser adorado, mais ele lhe apreciará".

Como se vê, a vida sexual dos homens gira em torno do pênis. É claro, portanto, que eles fiquem terrivelmente perturbados com qualquer modificação que observem na dinâmica eretiva. E algumas modificações biológicas são bem claramente discerníveis na terceira idade.

No jovem, quando há uma estimulação sexual efetiva, o pênis 
se eleva quase que instantaneamente (com 3 a 5 segundos ele já está ereto); depois dos 50 anos a ereção se faz de modo mais lento, mas em compensação uma vez ereto, o pênis se mantém em ereção, sem ejacular, por um bom espaço de tempo. A ejaculação prematura não é uma disfunção que aparece na terceira idade. Quem a tem na velhice, aprendeu a ser ejaculador prematuro quando jovem.

Há inegáveis vantagens de permanecer mais tempo em estado eretivo de que ter simplesmente uma ereção rápida. Que falem as mulheres. O que acontece no idoso é que o sangue entra com dificuldade no corpo cavernoso, mas também dele sai com mais dificuldade. As coisas estão mais "enferrujadas", mas até que isto é uma vantagem porque permite um ato sexual mais demorado. É claro que há, no idoso, uma tendência maior para as disfunções ejaculatórias do tipo retardado ou bloqueado. A propósito, tive um cliente idoso que demorava de tal forma a ejacular, que passaria horas no exercício sexual não fosse o cansaço físico e a artrite. Para que a parceira, feliz com aquela ereção permanente, não desconfiasse de sua incapacidade ejaculatória, ele simplesmente simulava que estava sentindo orgasmo. Era a única maneira de parar o ato sexual.

Um outro fenômeno biológico que costuma assustar o idoso é que, mal ocorre a ejaculação, o pênis detumesce rapidamente "escorrendo para fora da vagina" com uma sem cerimônia de quem vai dormir cerca de 12 a 24 horas no mínimo, para que possa novamente ser acordado. Realmente, o período entre uma relação e outra, ou mais especificamente entre uma ereção e outra, o que é tecnicamente chamado de "período refratário", vai aumentando com a idade. Teoricamente, uma pessoa jovem pode ter uma relação sexual e repeti-la, com sucesso, pouco tempo depois, dependendo do estímulo erótico. À medida que a pessoa envelhece, aumenta o período refratário e há necessidade de uma estimulação sexual mais forte. Quando se chega à terceira idade, o período refratário é bastante longo e não adianta tentar acordar o pênis. Quando isto é feito, ele fica irritado, sensível e doloroso. "É mais um elemento irritado do que irritável”, afirma Brothers. Nenhum amante da liberdade pode ser tão cioso de sua autodeterminação do que o pênis. Quando não quer subir, não sobe. Não adianta suplicar, elogiar, trapacear, gritar ou implorar. Ele permanece em desatento silêncio, mudo, alheio a apelos e ameaças. E quanto mais o indivíduo fica ansioso, quanto mais insiste, mais 'o miserável vai se aninhar entre as dobras peludas do escroto.

Uma outra modificação notável da resposta sexual do idoso ocorre durante a ejaculação. O volume seminal é reduzido (de 3 a 5 
$\mathrm{ml}$ no jovem, para 2 a $3 \mathrm{ml}$ após os 50 anos, às vezes até menos). Em certas pessoas a redução é tão drástica que quem está de longe pode ter a impressão de que o pênis está engasgado, tossindo no seco...

Também a freqüência das contrações expulsivas é menor. Enquanto no jovem o esperma é lançado a uma distância de 30 a 60 centímetros do meato uretral, depois dos 50 anos, quase nunca alcança uns miseráveis 15 a 20 centímetros. E o indivíduo se dê por feliz, porque às vezes nem isto. É necessário, porém, lembrar que estas mudanças não alteram o prazer do orgasmo.

Antes de me despedir da parte orgânica quero aqui fazer uma menção a uma pequena glândula que, ligada ao aparelho reprodutor, às vezes conspira contra a atividade sexual do idoso. Estou me referindo à próstata. Próstata inflamada é sexo doloroso a inflamação é caminho para hipertrofia, retenção urinária e outras coisas. A inflamação regride, mas o tecido cicatricial e a fibrose que invade a glândula permanece para sempre. Depois dos 60 aos, $40 \%$ dos homens são prostáticos, afirmam os urologistas. Mas não há motivos de desespero porque a pessoa pode não precisar de fazer cirurgia. Há um tratamento eficiente para as próstatas aumentadas. Seu nome é massagem. Na forma clássica, o médico introduz o dedo no reto do cliente e através dele (o reto) massageia a glândula, fazendo sair o líquido prostático retido.

Mas há um tratamento muito melhor. É a automassagem prostática a não pensem que é o próprio indivíduo quem introduz o dedo. Esta automassagem se efetua funcionalmente através do ato sexual. A cada ejaculação a próstata se contrai violentamente e se automassageia. Não há, portanto, mais agradável forma de profilaxia contra a hipertrofia prostática que o ato sexual freqüente. Profilaxia também contra outros males do corpo. Contra o enfarte, por exemplo, porque se a causa do enfarte for a falta de exercício, o excesso de peso ou a tensão nervosa, o melhor remédio é ainda o ato sexual. Remédio gratuito e agradável que, além de ajudar a conservar a forma física queimando calorias, é um exercício suave e produtivo e, ainda por cima, relaxante de todas as tensões existentes. Também para os artrítcos é uma vantagem. Não sei onde li que o ato sexual parece provocar uma maior produção suprarrenálica de adrenalina. Se isto não for verdadeiro pouco importa, o importante é a doçura da crença.

E por falar em crença está na hora de entrarmos no estudo da sexualidade sob o ponto de vista sócio-cultural. 


\section{COMPONENTE SÓCIO-CULTURAL}

O grande tumulto emocional que caracteriza a vida sexual do homem na terceira idade decorre de dois fatores principais. $\mathrm{O}$ primeiro fator é a falta de conhecimento das modificações fisiológicas que ocorrem na atividade sexual do indivíduo e o segundo são as pressões culturais.

A cultura é extremamente marcante e, tanto quanto a vida biológica, interfere na formação da personalidade do ser humano. A velhice de um esquimó é certametne distinta da velhice de um xavante que, por sua vez, é muito diferente da velhice chinesa, da saxônica, da latino-americana. Todos apresentam as mesmas modificações biológicas, mas sob esta matriz orgânica se inscreve um modelo cultural distinto. Mitos, crendices, normas, costumes, tudo faz com que o idoso de uma cultura seja diferente do homem idoso de outra cultura.

Assim, na chamada civilização judaico-cristã, está na própria massa sangüínea a associação do sexo com a reprodução. E por ser considerada como sendo essencialmente reprodutiva é que não se valoriza a sexualidade não genitálica. O compromisso da vida sexual com a reprodução é tão evidente que a atividade sexual do homem tern de incluir necessariamente pênis ereto, capaz de lançar espermatozóides no estojo vaginal.

Não é de admirar, portanto, que o indivíduo ao envelhecer, ao começar a caudicar a rigidez peniana, ao aumentar o espaço entre as relações sexuais comece também a entrar em desespero.

Muito mais importante que a chamada liberação sexual dos anos 70 é a necessidade de se redefinir as finalidades da sexualidade humana, para retirá-la da servidão biológica que lhe foi imposta por séculos a séculos de confinamento cultural.

Tem sido afirmado com muita razão que, em virtude dos estereótipos sociais, muitos velhos morrem antes de morrer. Na verdade, além do "estresse somático" resultante natural do processo de envelhecimento, o idoso é submetido também ao "estresse cultural", em virtude da deificação que a sociedade empresta à juventude.

Numa sociedade consumista como a nossa, juventude significa produção de bens. Quem não produz não é nada. É coisa, é borda, é margem... Meninos e velhos são coisas, são grupos marginalizados. Os meninos ainda são aceitáveis na medida em que são considerados um investimento social, a longo ou curto prazo, o que não ocorre com o velho.

Normalmente o indivíduo que se aposenta, e que não tem uma outra ocupação produtiva, por decreto social se transforma em coisa. 
E tudo isto é feito com um sentido de falso paternalismo. Talvez melhor fosse em outras épocas em que as pessoas não se aposentavam: simplesmente elas caíam mortas no trabalho. Melhor porque não perdiam o respeito público. Quando o indivíduo se aposenta, ele é considerado velho por decreto social. A partir daí ele deve ficar quieto, marginalizado, parado, descansando, enferrujando. A sociedade lhe exige, em troca da pensão da previdência, que ele faça uma autonegação de sua sexualidade. E não vai demorar muito para que um desses burocratas irrealizados comece a exigir do aposentado, como condição prévia para receber o benefício, um atestado de "brochura", porque se ele não for "brocha" pode trabalhar e se pode trabalhar não há porque estar aposentado.

Em nossa cultura há uma associação freqüente do sexo não só com a juventude, mas também com o vigor físico. "A masculinidade é muitas vezes equiparada a uma proeza física". Mede-se o homem pelo número de relações e não necessariamente pela qualidade das relações. Se um indivíduo é capaz de ter muitas relações com muitas mulheres, mesmo que ele seja um ejaculador precoce, ele é considerado como o protótipo do macho. Dom Juan e Casanova não são deste tipo?

E compreensível, portanto, que os homens idosos se julguem e sejam julgados, tomando-se o jovem como padrão.

A proeza sexual é necessária para provar a virilidade. "Homem de 92 anos é pai de gêmeos", "Octogenário casa com vedete de 22 anos". Isto dá notícia, isto envaidece o idoso tanto quanto receber a mais alta condecoração nacional. Interessante observar, no entanto, que por trás deste aplauso social, há também uma certa ponta de reprovação. "O antagonismo da sociedade ao sexo na velhice pode ser sintetizado em poucas palavras: o que era virilidade aos 25 anos é luxúria aos 75". O idoso se transforma logo no "bode velho", "tarado". Não falta quem diga que: "o velho não vai dar conta...", "é muito avião para pouco passageiro...". É que na mente das pessoas a sexualidade dos velhos "caminha pela tênue fronteira entre o heroísmo sexual e a indecência”.

A maior parte dos problemas sócio-culturais da terceira idade não decorre propriamente do declínio físico, mas da inexorável pressão que o grupo social exerce. Numa civilização cuja sociedade está estruturada em torno dos jovens, ser velho é simplesmente horrível.

Afinal, desde pequeno se aprende que a juventude é boa e que a velhice é ruim, que a juventude é bela e que a velhice é feia. Até nos contos de fada, a personagem feia, cruel e perversa é sem- 
pre o velho. Bruxo só tem graça se for velho. Feiticeira de respeito, só velha. E quanto mais velho ou velha, melhor. Quem já viu, por exemplo, Chapeuzinho Vermelho com 50 anos? Pensem só como perderia a poesia imaginar Branca de Neve sendo acordada por um príncipe de 70 anos.

Nahoum tinha razão quando afirmava que "a velhice se define pela lealdade, pela decadência, pela proximidade da morte".

Velho que aspira a uma vida sexual é considerado depravado. Até que a mulher idosa, neste particular, é mais feliz. Simplesmente a sociedade decretou que ela não tem mais sexo, de modo que se ela desejar ter um relacionamento amoroso é acusada de arterioesclerótica. Mas o homem idoso, além de arterioesclerótico, é depravado.

Sexo no velho é ridículo. Nahoum afirmava que "a sociedade ri das aventuras dos gerontos, ironiza suas paixões, e médicos chegam até a proibir a atividade sexual deles: restrição a mais para isolar quem já tem escasso relacionamento com os outros".

E interessante observar que numa sociedade machista como a nossa, uma mulher idosa que sai com um homem mais jovem corre o risco de ser ridicularizada, mas se é um homem idoso que sai com uma mulher bem mais jovem, ele corre o risco de ser aplaudido.

É típico o estereótipo do velho senil molestador de crianças. É interessante notar que muitas pessoas idosas, na solidão e na indigência emocional em que se encontram, buscam nas crianças o calor e o afeto. É como se os extremos da vida se tocassem. Se é uma mulher idosa quem acaricia uma criança, o gesto é tido como normal, mas, se é um velho, seu gesto simples, que raramente tem "semitons eróticos", é logo interpretado como debochado e sexual. Delinqüentes sexuais idosos existem, mas eles são muito mais raros do que se pensa. Apenas um sexto dos pedófilos têm mais de 50 anos. A esmagadora maioria está na faixa etária dos 20 a 24 anos.

$\mathrm{O}$ fato é que a terceira idade é socialmente associada com a idade da assexualidade. E quando todo mundo diz que o idoso tem que ser assexuado, o indivíduo começa a ficar inseguro quando nota que ainda conserva suas capacidades sexuais. Sou normal? Isto passa a ser uma grande dúvida... Durante anos e anos a cultura impregnou seu espírito, a sociedade fez da sexualidade do homem o que bem quis, agora é preciso saber "o que o homem fará daquilo que fizeram dele". É esta vivência de cada um que vai compor sua fisionomia psicológica. 


\section{COMPONENTE PSICOLÓGICO}

Podemos repetir Montaigne quando afirmava que "a velhice pôe mais rugas no espírito do que no rosto". Como o indivíduo se vê, como ele gostaria de ser visto, como ele pensa que os outros o vêem, tudo isto tem uma significação psicológica profunda no idoso. As mudanças físicas e sociais exigem uma série de ajustamentos psicológicos.

Ao se adaptar à imagem atual de si mesmo, o indivíduo tende a criar um novo sentido estético. Mas não é só isto. Novos reajustamentos devem ser feitos e a velhice passa a ser uma espécie de estado de espírito. Velho é aquele que se julga velho e se comporta como velho. Velho é aquele que se entrega à pressão social, se socializa, se massifica, se estereotipa, se anula na coletividade social. O velho não é só um rejeitado social, mas é também e sobretudo um ser que, por ter perdido sua auto-estima e sua autoconfiança, se autorejeita.

O grande Cícero, ao escrever seu famoso ensaio De Senectude, já afirmava que a velhice pode ser uma etapa de grandes realizações e de novos interesses, destinada a conservar o homem em plena atividade criativa.

No que concerne especificamente ao sexo, não há porque renunciar. E interessante observar a psicologia do homem que ainda não chegou à terceira idade, mas que dela se aproxima. Há uma verdadeira ansiedade de renovação. Diz-se que o homem está em uma espécie de "climatério", na chamada "idade do lobo", porque ele, predatoriamente, sai tentando novas conquistas amorosas. Ele não consegue resistir aos apelos da variação. Sente-se mais viril na medida em que nota que é capaz de conquistar uma mulher mais jovem. "É uma espécie de regressão à criança que existe dentro dele, semelhante à maneira como reagiu fazendo xixi na cama quando sua irmã nasceu. Agora, retrocede perseguindo garotas...".

Estou convencido que estas aventuras são do tipo aspirina. "Apenas dão alívio sintomático, temporário". Na verdade o que esta em jogo é o medo de envelhecer, de notar o desmoronamento do corpo, a começar pelo desmoronamento do pênis.

Quando se ultrapassa esta fase climatérica, o tempo corre rápido. E, associado às modificações físicas e aos mitos culturais, surgem problemas concretos que impossibilitam manter uma vida sexual com a regularidade desejável. E grande a possibilidade da pessoa se encontrar sem parceira na terceira idade. A viuvez é muitas vezes um motivo para que o indivíduo encerre sua vida sexual. Outras vezes é a companheira que se desinteressou pelos assuntos sexuais, ou que, 
doente, já não pode se prestar à realização plena dos desejos eróticos... Em outros casos é a habituação, o aspecto físico da parceira, suas varizes, suas hermorróides, seus problemas auditivos, suas artrites. A busca de uma nova relação é obstaculizada pelos filhos, pelos amigos, pela sociedade. O idoso oculta o seu desejo para evitar a crítica dos parentes e do que possam pensar dele. Usualmente, não resta muitas alternativas a não ser a prática masturbatória solitária, arrancando da memória a imagem das jovens mocinhas do seu tempo.

Com freqüência, a vida sexual do idoso fica esclerozada. É preciso que se reverta urgentemente este quadro sombrio que a nossa sociedade e a nossa cultura criaram para que o idoso vivesse seus últimos dias. Cada um vive a sua vida na medida de seus desejos. Não há porque haver subserviência a padrões estereotipados. Há que se fazer uma revolução no conceito de terceira idade. A velhice não deve ser definida, como dizia Frank, "como sendo um período de vida em que se foge tanto mais do futuro quanto mais ele se aproxima".

A terceira idade deve ser um período de realizações em todos os campos, inclusive no sexual. Deve ser também um período de doces recordações, porque, afinal, como dizia Sófocles, "só se sabe como o dia foi maravilhoso depois que anoitece". 